\title{
Prevalence of late-onset pompe disease in Portuguese patients with diaphragmatic paralysis - DIPPER study
} \author{
A. Marinhog ${ }^{g}$ J.M. Silva ${ }^{h}$, N. Pires ${ }^{i}$, S. André ${ }^{j}, C$. Loureiro ${ }^{f}$ \\ a Hospital Guimarães, Centro Hospitalar do Alto Ave, Guimarães, Portugal \\ b Universidade do Porto, Porto, Portugal \\ c Centro Hospitalar de Trás-os-Montes e Alto Douro, Vila Real, Portugal \\ ' Hospital de Santa Marta, Centro Hospitalar de Lisboa Central, Lisboa, Portugal \\ e Hospital Egas Moniz, Centro Hospitalar de Lisboa Ocidental, Lisboa, Portugal \\ ${ }^{f}$ Centro Hospitalar e Universitário de Coimbra, Coimbra, Portugal \\ g Centro Hospitalar de São João, Porto, Portugal \\ h Hospital Sousa Martins, Unidade Local de Saúde da Guarda, Guarda, Portugal \\ i Hospital de Santa Maria Maior, Barcelos, Portugal \\ j Centro Hospitalar do Porto, Porto, Portugal
}

M.J. Guimarães ${ }^{a, *}, J$.C. Winck ${ }^{b}$, B. Conde $^{c}$, A. Mineiro ${ }^{d}$, M. Raposo ${ }^{e}$, J. Moita $^{f}$,

Received 26 July 2016; accepted 15 February 2017

Available online 9 May 2017

\section{KEYWORDS \\ Diaphragmatic; \\ Paralysis; \\ Pompe}

\begin{abstract}
Pompe disease is a rare autosomal recessive neuromuscular disorder caused by acid $\alpha$-glucosidase enzyme (GAA) deficiency and divided into two distinct variants, infantile- and late-onset. The late-onset variant is characterized by a spectrum of phenotypic variation that may range from asymptomatic, to reduced muscle strength and/or diaphragmatic paralysis. Since muscle strength loss is characteristic of several different conditions, which may also cause diaphragmatic paralysis, a protocol was created to search for the diagnosis of Pompe disease and exclude other possible causes.

Methods: We collected a sample size of 18 patients (10 females, 8 males) with a median age of 60 years and diagnosis of diaphragmatic paralysis of unknown etiology, followed in the Pulmonology outpatient consultation of 9 centers in Portugal, over a 24-month study period. We evaluated data from patient's clinical and demographic characteristics as well as complementary diagnostic tests including blood tests, imaging, neurophysiologic and respiratory function evaluation. All patients were evaluated for GAA activity with DBS (dried blood test) or serum quantification and positive results confirmed by serum quantification and sequencing.

Results: Three patients were diagnosed with Pompe's disease and recommended for enzyme replacement therapy. The prevalence of Pompe, a rare disease, in our diaphragmatic paralysis patient sample was $16.8 \%$.
\end{abstract}

\footnotetext{
* Corresponding author.

E-mail address: zezaguimaraes@gmail.com (M.J. Guimarães).

http://dx.doi.org/10.1016/j.rppnen.2017.02.004

2173-5115/@ 2017 Sociedade Portuguesa de Pneumologia. Published by Elsevier España, S.L.U. This is an open access article under the CC BY-NC-ND license (http://creativecommons.org/licenses/by-nc-nd/4.0/).
} 
Conclusion: We conclude that DBS test for GAA activity should be recommended for all patients with diaphragmatic paralysis which, despite looking at all the most common causes, remains of unknown etiology; this would improve both the timing and accuracy of diagnosis for Pompe disease in this patient population. Accurate diagnosis will lead to improved care for this rare, progressively debilitating but treatable neuromuscular disease.

( 2017 Sociedade Portuguesa de Pneumologia. Published by Elsevier España, S.L.U. This is an open access article under the CC BY-NC-ND license (http://creativecommons.org/licenses/bync-nd/4.0/).

\section{Introduction}

Pompe disease is a rare autosomal recessive neuromuscular disorder caused by acid $\alpha$-glucosidase enzyme (GAA) deficiency, resulting in the accumulation of glycogen in the lysosomes of numerous, but primarily muscular, tissues. ${ }^{1}$ It is often termed glycogen storage disease type II (GSDII) or acid maltase deficiency. ${ }^{2,3}$

Depending on the age of onset, Pompe is divided into infantile and late-onset ${ }^{4}$ disease. Infantile onset Pompe disease represents the most severe form and almost invariably leads to death, due to cardio-respiratory failure, within one year. The late-onset variant presents at any time after the age of one year, and is characterized by a spectrum of phenotypic variation. It may range from asymptomatic patients with increased creatine kinase (CK) to muscle cramps and pain syndrome or rigid-spine syndrome. ${ }^{5-7}$ The lower limbs and paraspinal muscles are frequently affected first, followed by the respiratory muscles, particularly the diaphragm, intercostal and accessory muscles. Respiratory failure is the main cause of increased morbidity and mortality ${ }^{8,9}$ and the main cause of respiratory failure is diaphragmatic weakness. ${ }^{10}$

The diaphragm is the major muscle of ventilation constituted by a dome-shaped structure of tendons and muscle innervated by the phrenic nerves which provide sensory, sympathetic and motor function. Diaphragm contraction expands the chest increasing pleural negative pressure and promoting air flow into the lungs. Whenever there is diaphragmatic weakness the diaphragm fails to contract appropriately, causing reduced inspiratory volume and possible dyspnea. An extreme form of diaphragmatic weakness is unilateral or bilateral diaphragmatic paralysis. ${ }^{11}$ Several different conditions may present with respiratory failure and distinguishing among them is important to determine the correct therapeutic options. ${ }^{12}$ Pompe disease is in the differential diagnosis of a wide variety of myopathies, and therefore accurate diagnostic tools are needed for an effective screening of this condition. Particularly when the progressive involvement and weakness of respiratory muscles and diaphragm, characteristic of the disease, are closely related to respiratory dysfunction which affects sleep, daily life activities, and overall quality of life.

The prevalence of this condition in the general population is unknown, and varies according to clinical presentation and ethnicity. The late-onset form has an estimated incidence of $1 / 57000 .{ }^{13}$ In Portugal, there is no accurate data on the prevalence of Pompe disease, but it is estimated that there are 27 cases of patients under enzyme replacement therapy (ERT). ${ }^{14-16}$
Therefore, the primary objective of this study was to estimate the prevalence of this disorder in patients with a diagnosis of diaphragmatic paralysis of unknown etiology followed in the outpatient setting of a Pulmonology clinic, and to characterize the clinical and socio-demographic profile of these patients. A secondary objective was to create an algorithm for the accurate diagnosis of late-onset Pompe disease in patients with diaphragmatic paralysis of unknown etiology, which will lead to better management and treatment of patients with this neuromuscular disease.

\section{Materials and methods}

This was a national, multicenter, epidemiological study of patients with a diagnosis of diaphragmatic paralysis of unknown etiology. The study population was identified from the Pulmonology outpatient consultations of 9 centers in Portugal over a 24-month study period. Patients were consecutively enrolled if they were $\geq 18$ years of age, gave informed consent to participation, and fulfilled one of the following inclusion criteria: diagnosis of (unilateral or bilateral) diaphragmatic paralysis of unknown cause; diagnosis of restrictive lung disease (both FVC [forced vital capacity] and TLC [total lung capacity] $<80 \%$ of predicted, or $\geq 12 \%$ decrease in VC [vital capacity] in the supine position), decreased maximal inspiratory pressure (IPmax) or sniff nasal inspiratory pressure (SNIP) (at least $-10 \mathrm{~cm}$ of $\mathrm{H}_{2} \mathrm{O}$ than predicted) of unknown origin; diagnosis of progressive chronic myopathy with respiratory involvement, particularly of the diaphragm, with either inconclusive muscle biopsy or a diagnosis based on the generic definition of inclusion body myositis.

Patients were excluded from the study if they were unable or unwilling to provide informed consent, were tracheostomized or pregnant, required invasive mechanical ventilation, or suffered from one of the following conditions: neuromuscular junction diseases (Eaton-Lambert syndrome, myasthenia gravis), myopathies (polymyositis and other mixed connective tissue diseases, dystrophy mitochondrial myopathies, amyloidosis), spinal cord myelopathy (cervical spine injury, sarcoidosis, syringomyelia, polyomyelitis, amyotrophic lateral sclerosis), peripheral neuropathy [cervical spine injury, mediastinal tumor, Guillain-Barré syndrome, nutritional neuropathies (vitamin B12 deficiency) and lead neuropathy] or active neoplastic disease.

Information retrieved from patients included sociodemographic and clinical history, as well as physical exams 
Table 1 Patients' socio-demographic characteristics.

\begin{tabular}{lc}
\hline & $n(\%)$ \\
\hline Total no. of patients & $18(100)$ \\
Male & $8(44)$ \\
Female & $10(56)$ \\
Median age, years (range) & $60(43-81)$ \\
Race & \\
Caucasian & $18(100)$ \\
Region & \\
Braga & $7(38.9)$ \\
Porto & $4(22.0)$ \\
Lisbon & $3(16.7)$ \\
Coimbra & $1(5.6)$ \\
Guarda & $1(5.6)$ \\
Leiria & $1(5.6)$ \\
Vila Real & $1(5.6)$ \\
\hline
\end{tabular}

and diagnostic parameters (including respiratory function tests, polysomnography, ultrasound scan, chest radiograph and blood biochemistry), all collected as part of the routine clinical practice for diaphragmatic paralysis diagnosis. Acid $\alpha$-glucosidase activity was determined in dried-blood spots (DBS) for the diagnosis of Pompe disease, ${ }^{17}$ and a further confirmation through GAA gene sequencing was done if the blood-based GAA enzyme assay showed reduced activity. ${ }^{18}$

\section{Respiratory function tests}

Respiratory function tests were conducted using body plethysmography with vital capacity determination in seated versus supine position. The single-breath method was used to measure the alveolo-capillary diffusion of $\mathrm{CO}$ (DLCO-SB) and thoracic pressures were ascertained either by maximal inspiratory pressure (MIP) or by sniff nasal inspiratory pressure (SNIP) followed by maximal expiratory pressure (MEP).

\section{Statistical analysis}

Statistical analysis was performed using SPSS 15.0 software. Continuous variables were described as medians and interquartile ranges, and categorical variables were described as numbers and (proportions with) percentages. A multivariate analysis was performed to evaluate the association between diaphragmatic paralysis and muscle strength loss characteristic of Pompe disease.

\section{Results}

A total of 18 patients with diaphragmatic paralysis were included in the DIPPER study by the collaborative Portuguese centers. Patients' socio-demographic baseline characteristics are reported in Table 1. Eight (44\%) patients were male and 10 (56\%) were female, the median age was $60.8 \pm 11.1$ (range 43-81) years, all patients were Caucasian and mainly from the North of Portugal.

Patient clinical history is summarized in Table 2. Briefly, most patients $(27.8 \%$ ) were grade 3 (walks slower than most
Table 2 Patients' clinical characteristics.

\begin{tabular}{ll}
\hline & $n(\%)$ \\
\hline MRC dyspnea scale & \\
1 & $4(22.2)$ \\
2 & $3(16.7)$ \\
3 & $5(27.8)$ \\
4 & $2(11.1)$ \\
Daytime symptoms & \\
Anxiety & $8(44.4)$ \\
Irritability & $5(27.8)$ \\
Headache & $6(33.3)$ \\
Nocturnal symptoms & \\
Anxiety & $6(33.3)$ \\
Snoring & $8(44.4)$ \\
Insomnia & $6(33.3)$ \\
Non-restorative sleep & $7(38.9)$ \\
Personal history & \\
Comorbidities (hypertension, \\
depression, diabetes, dyslipidemia, \\
hypothyroidism) \\
History of trauma \\
$\begin{array}{l}\text { Previous surgeries } \\
\text { Family history }\end{array}$ \\
$\begin{array}{l}\text { Neuromuscular conditions } \\
\text { Metabolic diseases (diabetes, } \\
\text { hypertriglyceridemia, hypothyroidism, } \\
\text { dyslipidemia) } \\
\text { Obstructive sleep apnea syndrome } \\
\text { Arterial hypertension }\end{array}$ \\
Sudden death & $14(77.8)$ \\
\hline &
\end{tabular}

people on the level, stops after a mile or so, or stops after 15 min walking at own pace) in the MRC dyspnea scale, and $57.1 \%$ experienced anxiety as the main daytime symptom. Excessive daytime sleepiness (EDS) was measured through the Epworth sleepiness scale (ESS) with a median value of 7 and an interquartile range of 4-13, the maximum value for the Epworth scale attained by any patient was 19 . Several nocturnal symptoms were reported, snoring $(61.5 \%)$ and non-restorative sleep (53.8\%) being the most frequent. Arterial hypertension was the most frequent health precedent, and metabolic diseases the most frequent family precedent $(n=4,22.2 \%)$.

\section{Physical examination}

Overall physical status was assessed in 14 patients by empirical observation with 9 (64.3\%) patients reported as having good physical function, and 5 (35.7\%) reported to have modest physical function. Anthropometrics of these patients are depicted in Table 3.

The Mallampati score, used to predict the ease of intubation, was assessed in 13 patients and showed that most of them $(n=5,38.5 \%)$ were class 2 (soft palate, fauces, portion of uvula), 4 (30.8\%) patients were class 3 (soft palate, base of uvula), 3 (23.1\%) patients were class 1 (soft palate, fauces, uvula, pillars), and only 1 (7.7\%) patient was class 4 (hard palate only). 
Table 3 Anthropometrics of the 14 patients who performed the physical examination.

\begin{tabular}{lc}
\hline & Median (range) \\
\hline Weight $(\mathrm{kg})$ & $72.5(48.0-119.0)$ \\
Height $(\mathrm{cm})$ & $160.0(144.0-175.0)$ \\
Body surface $\left(\mathrm{m}^{2}\right)$ & $1.7(1.4-2.0)$ \\
Body mass index, BMl $\left(\mathrm{kg} / \mathrm{m}^{2}\right)$ & $29.0(19.0-37.0)$ \\
Blood pressure $(\mathrm{mmHG})$ & \\
$\quad$ Max & $129.0(105.0-158.0)$ \\
$\quad$ Min & $80.0(53.0-104.0)$ \\
Oxygen saturation $(\%)$ & $94.0(84.0-97.0)$ \\
Fraction of inspired oxygen $\left(\mathrm{FiO}_{2}\right)$ & $21.0(21.0-28.0)$ \\
Cervical perimeter $(\mathrm{m})$ & $35.5(18.0-45.0)$ \\
\hline
\end{tabular}

Neurologic evaluation revealed that most patients had difficulty getting up $(n=8,61.5 \%)$ and sitting $(n=7,53.8 \%)$. Concerning upper limbs, cases of muscular atrophy were observed in $3(23.1 \%)$ patients, mainly in arms, forearms and hands, 8 (72.7\%) patients had sustained muscular strength, and 10 (76.9\%) patients had normal reflexes. Concerning lower limbs, muscular atrophy was observed in 3 (23.1\%) patients, 9 (69.2\%) patients had sustained muscular strength, and 9 (69.2\%) patients had normal reflexes. An abnormal gait was identified in 7 (58.3\%) patients, mainly due to ataxia and weakness in both feet ( $n=2,28.6 \%$, each), but also due to Trendelenburg walk in one patient, paraparesis in one patient, and as a consequence of bimalleolar osteoporotic fracture in one patient. Nine (69.2\%) patients were unable to run, with main causes being fatigue, dyspnea, and sequels from bimalleolar osteoporotic fracture.

\section{Complementary diagnostic tests}

Fifteen of the 18 patients included in this study performed complementary diagnostic tests, including complete blood count (CBC) and blood biochemistry (Table 4), blood serology and thyroid function assessment. For $88.9 \%$ of these patients, thyroid function was within the normal range. One patient had positive serology for HBV, and another for HCV. Immunoglobulins were within the normal range for 13 patients and were abnormal for two patients, and abnormal levels of autoantibodies were also observed in two patients.

Creatine kinase (CK) levels were elevated in these patients, with a mean CK of $249.8(\mathrm{SD}=332.9) \mathrm{U} / \mathrm{L}$, and a median of 152 (range: 24-1290) U/L.

The chest X-ray revealed abnormal results in 13 patients, due to (right, left or both) hemidiaphragm elevation. In all patients diaphragmatic paralysis were confirmed by thoracic CT scan (Fig. 1) or thoracic ultrasound (Fig. 2) and changes in diaphragmatic movement ascertained.

\section{Respiratory function tests}

Respiratory function tests were mandatory to assess whether there was a deterioration of patients' respiratory condition. They may be indicative, for instance, of diaphragmatic weakness by showing a difference between forced vital capacity (FVC) in sitting and supine position - i.e. postural
Table 4 Complementary diagnostic test results for the 15 patients who performed them.

\begin{tabular}{|c|c|}
\hline & Median (range) \\
\hline \multicolumn{2}{|l|}{$C B C$} \\
\hline Hemoglobin $(\mathrm{g} / 100 \mathrm{ml})$ & $13.6(10.1-16.8)$ \\
\hline Leukocyte count & $6725(1160-11400)$ \\
\hline Neutrophil count & $3820(824-4964)$ \\
\hline Lymphocyte count & $1425(209-1750)$ \\
\hline Platelet count & $237(160-2390)$ \\
\hline \multicolumn{2}{|l|}{ Blood biochemistry } \\
\hline Sodium (mmol/L) & $141(135-147)$ \\
\hline Creatinine $(\mathrm{mg} / \mathrm{dl})$ & $0.7(0.5-5.5)$ \\
\hline Potassium (mmol/L) & $4.4(3.4-5.0)$ \\
\hline Glucose (mg/DL) & $102.5(81-156)$ \\
\hline Protein $(\mathrm{g} / \mathrm{L})$ & $70(58-75.4)$ \\
\hline Albumin $(\mathrm{g} / \mathrm{L})$ & $42(35-62.2)$ \\
\hline Creatine kinase (CK) (IU/L) & $152(24-1290)$ \\
\hline Calcium (mmol/L) & $8.8(2.3-9.9)$ \\
\hline Phosphorus (mmol/L) & $3.2(0.9-34)$ \\
\hline Alkaline phosphatase & $63.5(34-117)$ \\
\hline $\begin{array}{l}\text { Gamma-glutamyl transferase } \\
\text { (GGT) (IU/L) }\end{array}$ & $28(8-209)$ \\
\hline $\begin{array}{l}\text { Alanine aminotransferase (ALT) } \\
\text { (IU/L) }\end{array}$ & $32(6-105)$ \\
\hline $\begin{array}{l}\text { Aspartate aminotransferase } \\
\text { (AST) (IU/L) }\end{array}$ & $25.5(15-94)$ \\
\hline Total bilirubin ( $\mu \mathrm{mol} / \mathrm{L})$ & $9.2(3.4-23.7)$ \\
\hline Direct bilirubin $(\mu \mathrm{mol} / \mathrm{L})$ & $0.2(0.18-0.21)$ \\
\hline Total cholesterol (mg/dL) & $228.5(119-319)$ \\
\hline Thyroglobulin (ng/dL) & $105.5(2.3-291)$ \\
\hline Sedimentation velocity (S) & $10(5-80)$ \\
\hline $\begin{array}{l}\text { Angiotensin-converting enzyme } \\
\text { (ACE) (unit/L) }\end{array}$ & $15(3-67)$ \\
\hline
\end{tabular}

drop - or by a decreased mean inspiratory pressure (MIP). Spirometry was used to measure how much and how quickly patients could move air out of their lungs, and lung function values obtained are shown in Table 5, as well as the number of patients in which this evaluation was collected.

Arterial blood gas analysis was performed at rest $\left(\mathrm{FiO}_{2}\right.$ : 21\%). Median $\mathrm{PaO}_{2}$ was 64.5 (52.0-92.0) $\mathrm{mmHg}$, median $\mathrm{PaCO}_{2}$ was $45.0(30.0-65.2) \mathrm{mmHg}$, median $\mathrm{O}_{2}$ saturation was $92.5(84.5-97.1) \%$, and median $\mathrm{H}_{2} \mathrm{CO}_{3}$ was 28.8 (23.5-36.0) $\mathrm{meq} / \mathrm{L}$.

Seven patients performed the 6-min walk (6MWDT) test using pulse oxymetry $\left(\mathrm{SpO}_{2}\right)$ monitors. Six-min walk distance test (6MWDT) was defined as the longest distance possible in 6MWDT without encouragement. Overall, patients walked a mean distance of $334(S D=129.8) \mathrm{m}$ and had a mean fall of oxygen saturation of $7.1 \%$ [ $91.4 \%$ before and $84.3 \%$ after the test].

\section{Polysomnography (PSG) test}

PSG results are shown in Table 6.

Electromyography was preformed in 6 patients and revealed normal results for 4 patients and altered results for the other 2 . 

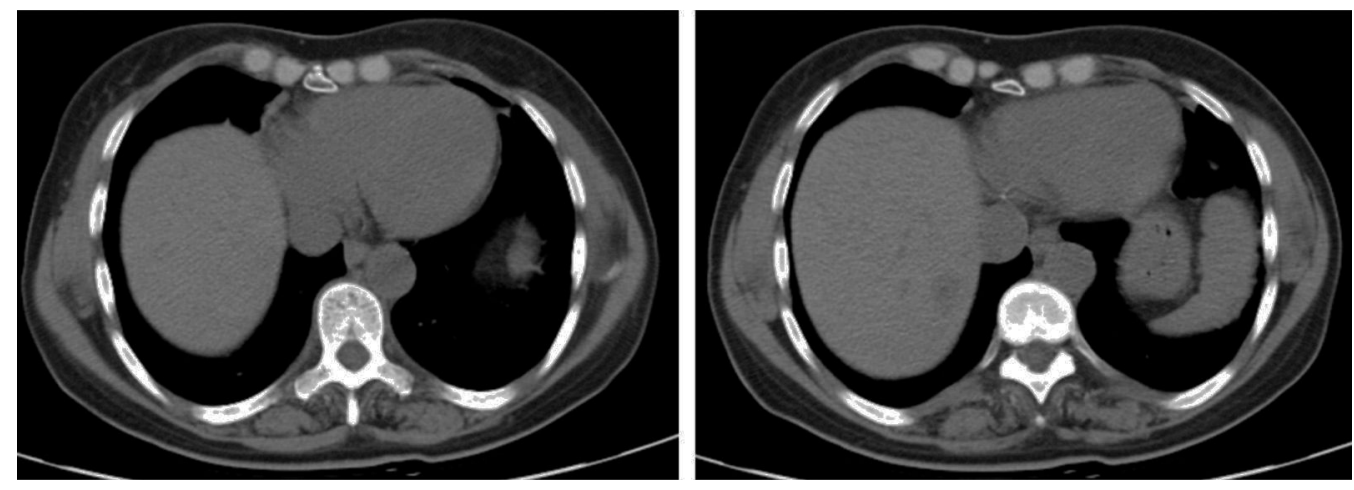

Figure 1 Thoracic CT scan showing right hemidiaphragmatic paralysis.
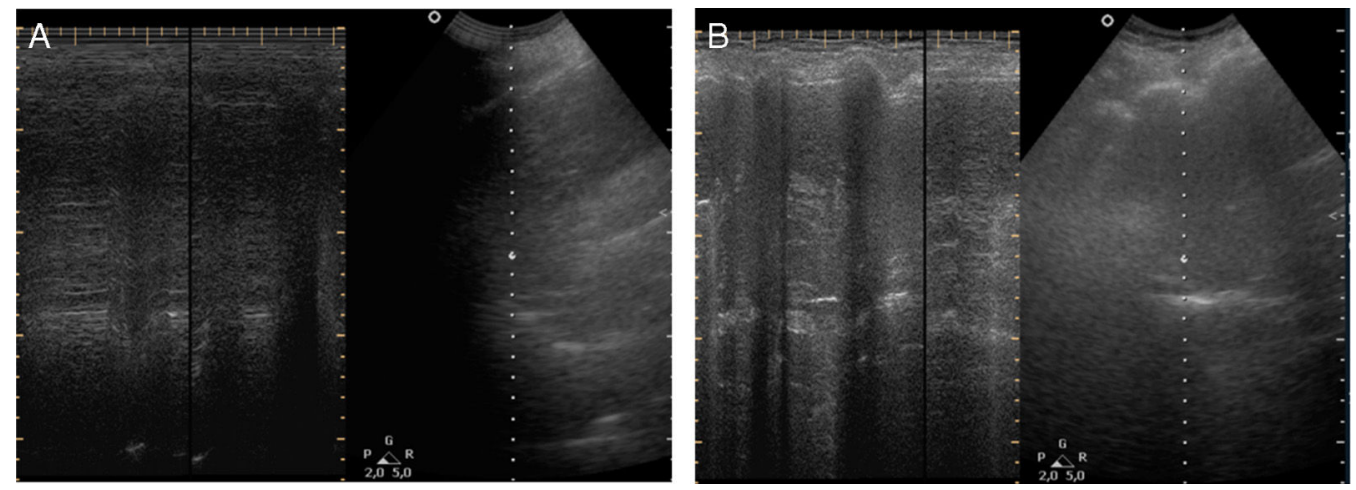

Figure 2 Thoracic ultrasound of patient with right diaphragmatic paralysis later confirmed as Pompe. There is decreased right diaphragm movement (A) and normal left diaphragmatic movement amplitude (B).

Table 5 Respiratory function tests (PFTs) results.

\begin{tabular}{lcr}
\hline & Median (range) & $n$ \\
\hline FEV1, l/s & $1.5(0.48-2.67)$ & 12 \\
FEV1, \% & $47(30.0-84.0)$ & 12 \\
FVC & $1.7(0.72-3.25)$ & 12 \\
FVC, \% & $46.9(29.0-90.0)$ & 13 \\
Drop in FVC from & $30.0(13.0-60.0)$ & 10 \\
$\quad$ & & \\
$\quad$ peated to supine & & \\
TLC, l & $3.3(2.55-4.27)$ & 5 \\
TLC, \% & $72.0(52.9-90.0)$ & 9 \\
RV & $1.9(1.12-2.0)$ & 7 \\
RV, \% & $92.2(35.0-104.0)$ & 8 \\
Ratio & $82.0(69.0-98.4)$ & 9 \\
DLCO-SB, \% & $67.9(27.8-120.0)$ & 10 \\
IP max, \% & $35.0(32.8-50.6)$ & 11 \\
EP max, \% & $76.0(30.1-135.0)$ & 11 \\
SNIP, \% & $30.5(20-41)$ & 2 \\
\hline FEV1 forced &
\end{tabular}

FEV1 = forced expiratory volume in one second; FVC = forced vital capacity; TLC=total lung capacity; RV=residual volume; $\mathrm{DLCO}-\mathrm{SB}=$ single-breath diffusing capacity of the lung for CO; IP $\max =$ decreased maximal inspiratory pressure; EP $\max =$ decreased maximal expiratory pressure; SNIP = sniff nasal inspiratory pressure; l/s = liters / second; l = liters. Ref. 46.
Table 6 Polysomnography (PSG) test results.

\begin{tabular}{lcc}
\hline & Median (range) & $n$ \\
\hline RDI & $7.1(3.1-11.0)$ & 2 \\
Desaturation index, \% & $12.0(9.3-17.5)$ & 5 \\
Time with $\mathrm{O}_{2}$ saturation $<90 \%, \%$ & $24.5(0.5-100.0)$ & 8 \\
Central sleep apnea, \% & $15.0(10.0-20.0)$ & 2 \\
Obstructive sleep apnea, \% & $49.5(0.05-60.0)$ & 4 \\
Mixed apneas, \% & $10.0(10.0-10.0)$ & 2 \\
Hypopnea & $15.0(9.4-61.1)$ & 4 \\
RERAs & $0.2(0.2-0.2)$ & 1 \\
\hline
\end{tabular}

$\mathrm{RDI}=$ respiratory disturbance index; RERA = respiratory effortrelated arousal.

Out of the 16 samples measured for dried blood spot (DBS) acid $\alpha$-glucosidase, four tested positive for Pompe disease, a fifth patient evidenced a small reduction of acid $\alpha$-glucosidase unconfirmed by serum GAA activity measurement, and the remaining 11 tested negative. The 2 remaining patients were tested for serum GAA activity (not DBS) and also tested negative for Pompe.

\section{Discussion}

The late-onset form of Pompe disease has a heterogeneous presentation, mimicking other neuromuscular diseases, leading to diagnostic challenge. Clinical manifestations vary in terms of organ involvement, age at onset and severity, 
and symptoms are often unspecific and may remain mild for decades, so that neither the patient nor the doctor considered going further with diagnostic procedures. An early diagnosis could be relevant due to the chance of improving or at least stabilizing the course of disease through enzymatic replacement therapy (ERT). ${ }^{19,20}$

Although Pompe disease is a rare condition, it has been reported in a number of different ethnic populations, namely Caucasian, Taiwanese, Korean and Japanese. ${ }^{21-31}$ This study is the first to investigate the incidence of lateonset Pompe disease in Portugal, based on respiratory signs/symptoms. One clinical study had previously investigated and identified four cases of the juvenile form of the disease in Portuguese patients, raising awareness of the fact that Pompe disease should be suspected in progressive myopathies at any age, especially those involving limb-girdle and respiratory muscles and in small infants with cardiomyopathy. ${ }^{29}$

In the present study, 18 patients with a mean age of $60.8 \pm 11.1$ years and diaphragmatic paralysis were identified and investigated for the late-form of Pompe disease. In Portugal, the diagnosis recommendations for late-onset Pompe disease suggest that patients with a progressive limbgirdle weakness, fatigue, cramps and muscle pain should be evaluated with creatinine kinase (CK) levels, electromyography, dynamic spirometry and muscle biopsy in inconclusive cases. ${ }^{16}$ Suspected cases and those in which muscle biopsy could not allow other diagnosis should be screened for lysosomal acid- $\alpha$-glucosidase deficiency with dried blood spot (DBS), and the diagnosis should be confirmed by determination of lysosomal acid- $\alpha$-glucosidase activity in a second sample and lysosomal acid- $\alpha$-glucosidase gene sequencing. According to this, 5 of the 18 patients investigated evidenced absence or reduction of GAA activity in the DBS test.

Muscular weakness was a common symptom in these patients, with $61.5 \%$ of patients showing difficulty in getting up and $53.8 \%$ in sitting down, in keeping with other studies that have reported muscular weakness as the most common initial symptom in late-onset Pompe patients. 8,32

Laboratory analysis revealed a mean CK value of 249.8 ( \pm 332.9 ; range: $24-1290$ ) $\mathrm{U} / \mathrm{L}$, which is suggestive of Pompe disease, since $C K$ values are typically elevated $(>250 \mathrm{U} / \mathrm{L}$, equivalent to 1.5-15 times the upper limit of normal in adults) in all forms of this disease.

The exercise capacity (normally measured using the 6min walk distance test [6MWDT]) and pulmonary function (forced vital capacity [FVC]) are outcome measures commonly used in studies of late-onset Pompe disease, by registering changes in the 6MWDT distance and in VC (measured as percentage change in predicted FVC [\% predicted FVC]). In this study, patients walked a mean distance of $334 \pm 129.8 \mathrm{~m}$, which is in accordance with the $246-340 \mathrm{~m}$ distance reported by other studies of late-onset Pompe patients. ${ }^{33-37}$ Although the 6MWDT is a valuable and widely used functional measure, it is associated with considerable inter- and intra-investigator variability, and does not elucidate the mechanisms behind the compromised physical function that it measures. ${ }^{38}$ Furthermore, the distance walked can be affected by factors such as patient motivation, age, sex, height, and weight as well as skeletal problems, ${ }^{39}$ which can affect gait and thereby influence the distance walked, as we noticed in this study.

FVC provides a simple measure of pulmonary function, and is a widely used outcome measure in studies of patients with neuromuscular disorders. Because diaphragm weakness often occurs early in the disease process and muscle weakness may not be evident until later in the disease course, respiratory evaluation is extremely important for patients who may have Pompe disease. Spirometric measurement of FVC in both the seated and supine positions is mandatory. A greater than $10 \%$ drop in FVC from the seated to the supine testing position is suggestive of diaphragm weakness and should raise the possibility of Pompe disease. ${ }^{40}$ Both measurements should be made regardless of whether respiratory symptoms are present. Because patients may have a normal seated FVC, the presence of diaphragm weakness can be missed if supine FVC is not measured. ${ }^{13,41}$ In this study, spirometry results revealed a $30 \%$ median drop in FVC when patients switched from the upright to the supine position, which is concordant with the diagnosis of diaphragm dysfunction.

Although not yet evaluated in late-onset Pompe disease, the sniff nasal inspiratory pressure (SNIP) test allows earlier detection of changes in respiratory muscle strength than FVC, and might be a useful measure to assess these patients. $^{42}$

In this study, we could not find a statistically significant correlation between any of the functional test results, for either pulmonary function or muscle weakness, and Pompe disease, but diaphragm involvement was confirmed in the results for all the patients included.

The gold standard for diagnosis in Pompe disease is the determination of partial or complete deficiency of GAA enzyme activity in blood or fibroblasts. In this study, 18 patients with diaphragmatic paralysis were screened for Pompe disease, 2 through $\alpha$-glucosidase serum activity measurements, 16 through the dried blood spot (DBS) $\alpha$-glucosidase test, with positive results for 5 patients. In one patient Pompe disease was not confirmed by subsequent serum activity quantifications (which were normal). In three of the four positive patients the diagnosis of Pompe disease was established by gene sequencing, and all were recommended for enzymatic replacement therapy by the National Council for Lysosomal Storage Diseases. The fourth patient revealed only one previously identified mutation (D91N) related to a pseudo deficiency of GAA, and the diagnosis for Pompe disease remains unclear.

Due to the low prevalence and wide range of symptoms, Pompe disease is often unrecognized by physicians. Therefore, the development of a diagnostic methodology represents a valuable tool to enhance the recognition of Pompe disease by pulmonologists and other physicians. The American Association of Neuromuscular and Electrodiagnostic Medicine has developed an algorithm to aid in the diagnosis of Pompe disease, ${ }^{13}$ and other algorithms have been developed in recent years to allow for an earlier detection of late-onset Pompe disease cases. ${ }^{6,13,43-45}$ In patients presenting with diaphragm paralysis or respiratory symptoms suggestive of diaphragm muscle involvement, Pompe disease should be included in the differential diagnosis and patients should undergo further laboratory, 
electrodiagnostic and pulmonary evaluations, and imaging studies, as appropriate.

A simple DBS test can improve both the timing and accuracy of the diagnosis, which will lead to an improvement in the care of patients who have this progressively debilitating neuromuscular disease.

\section{Limitations}

We were not able to establish a specific algorithm for the accurate diagnosis of late-onset Pompe disease in this population.

Another limitation of our study was that the non Pompe disease patients with diaphragm paralysis did not have a standardized neurological evaluation; these patients were followed by Pulmonologist only and it may be the case that a multidisciplinary evaluation is warranted for better characterization

Considering our primary objective, in this study we were able to diagnose Pompe disease in 3 of our pool of 18 patients (16.7\%).

Although results from this study should be interpreted with caution due to the small sample size, we would like to highlight that Pompe's Disease is rare, with only 27 estimated cases undergoing ERT in an overall national population of approximately 10 million, and is our firm belief that Pompe should be suspected in all patients with diaphragmatic paralysis of unknown etiology and that DBS should always be performed in these patients.

\section{Ethical responsibilities}

Protection of people and animals. The authors state that no human or animal experiments have been performed for this investigation.

\section{Confidentiality of the data}

The authors declare that no patient data appears in this article.

\section{Right to privacy and written consent}

The authors declare that no patient data appears in this article.

\section{Conflicts of interest}

Dr. Guimarães have received financial support for this investigation project, travel grants and honorariums for lecturing from Sanofi Genzyme ${ }^{\circledR}$ ref. GZ-2010-10243 - for DIPPER Dlaphragm Paralys is in Pompe Investigation.

\section{References}

1. Parenti G, Andria G. Pompe disease: from new views on pathophysiology to innovative therapeutic strategies. Curr Pharm Biotechnol. 2011;12:902-15.

2. Martiniuk F, Chen A, Mack A, Arvanitopoulos E, Chen Y, Rom WN, et al. Carrier frequency for glycogen storage disease type II in
New York and estimates of affected individuals born with the disease. Am J Med Genet. 1998;79:69-72.

3. Ausems MG, Verbiest J, Hermans MP, Kroos MA, Beemer FA, Wokke $\mathrm{JH}$, et al. Frequency of glycogen storage disease type II in the Netherlands: implications for diagnosis and genetic counselling. Eur J Hum Genet. 1999;7:713-6.

4. Schuller A, Wenninger S, Strigl-Pill N, Schoser B. Toward deconstructing the phenotype of late-onset Pompe disease. Am J Med Genet Part C Semin Med Genet. 2012;160C:80-8.

5. Van der Ploeg AT, Reuser AJ. Pompe's disease. Lancet. 2008;372:1342-53.

6. Bembi B, Cerini E, Danesino C, Donati MA, Gasperini S, Morandi L, et al. Diagnosis of glycogenosis type II. Neurology. 2008;71:S4-11.

7. Laforêt P, Doppler V, Caillaud C, Laloui K, Claeys KG, Richard $P$, et al. spine syndrome revealing late-onset Pompe disease. Neuromuscul Disord. 2010;20:128-30, http://dx.doi.org/ 10.1016/j.nmd.2009.11.006.

8. Herzog A, Hartung R, Reuser AJ, Hermanns P, Runz H, Karabul $\mathrm{N}$, et al. A cross-sectional single-centre study on the spectrum of Pompe disease, German patients: molecular analysis of the GAA gene, manifestation and genotype-phenotype correlations. Orphanet J Rare Dis. 2012;7:35.

9. Schüller A, Wenninger S, Strigl-Pill N, Schoser B. Toward deconstructing the phenotype of late-onset Pompe disease. Am J Med Genet C Semin Med Genet. 2012;160C:80-8.

10. Gaeta M, Musumeci O, Mondello S, Ruggeri P, Montagnese $F$, Cucinotta $M$, et al. Clinical and pathophysiological clues of respiratory dysfunction in late-onset Pompe disease: new insights from a comparative study by MRI and respiratory function assessment. Neuromuscul Disord. 2015;25:852-8, http://dx.doi.org/10.1016/j.nmd.2015.09.003.

11. Ben-Dov I. In: Molloy E, editor. Diaphragmatic paralysis symptoms, evaluation, therapy and outcome in congenital diaphragmatic hernia - prenatal to childhood management and outcomes. 2012. ISBN 978-953-51-0670-8.

12. Pfeffer G, Povitz M, Gibson GJ, Chinnery PF. Diagnosis of muscle diseases presenting with early respiratory failure. J Neurol. 2015;262:1101-14, http://dx.doi.org/10.1007/ s00415-014-7526-1.

13. American Association of Neuromuscular \& Electrodiagnostic Medicine. Diagnostic criteria for late-onset (childhood and adult) Pompe disease. Muscle Nerve. 2009;40:149-60.

14. Pinto R, Caseiro C, Lemos M, Lopes L, Fontes A, Ribeiro H, et al. Prevalence of lysosomal storage diseases in Portugal. Eur J Hum Genet. 2004;12:87-92.

15. Instituto Nacional de Saúde Ricardo Jorge [homepage na Internet]. Doenças lisossomais de sobrecarga (DLS) - Relatório 2011. Available from: http://www.insa.pt/ [accessed 13.01.14].

16. Brito-Avô L, Alves JD, Costa JM, Valverde A, Santos L, Araújo F, et al. Diagnosis recommendations for late-onset Pompe disease. Acta Med Port. 2014;27:525-9.

17. Bodamer OA, Dajnoki A. Diagnosing lysosomal storage disorders: Pompe disease. Curr Protoc Hum Genet. 2012, http://dx.doi.org/10.1002/0471142905.hg1711s75. Chapter 17:Unit 17.11.

18. Goldstein JL, Dickerson G, Kishnani PS, Rehder C, Bali DS. Blood-based diagnostic testing for Pompe disease: consistency between GAA enzyme activity in dried blood spots and GAA gene sequencing results. Muscle Nerve. 2014;49:775-6, http://dx.doi.org/10.1002/mus.24149.

19. Güngör D, Kruijshaar ME, Plug I, D’Agostino RB, Hagemans ML, van Doorn PA, et al. Impact of enzyme replacement therapy on survival in adults with Pompe disease: results from a prospective international observational study. Orphanet J Rare Dis. 2013;8:49, http://dx.doi.org/10.1186/1750-1172-8-49.

20. Jones HN1, Muller CW, Lin M, Banugaria SG, Case LE, Li $\mathrm{JS}$, et al. Oropharyngeal dysphagia in infants and children 
with infantile Pompe disease. Dysphagia. 2010;25:277-83, http://dx.doi.org/10.1007/s00455-009-9252-x.

21. Laforêt P, Nicolino M, Eymard PB, Puech JP, Caillaud C, Poenaru $L$, et al. Juvenile and adult-onset acid maltase deficiency in France: genotypephenotype correlation. Neurology. 2000;55:1122-8.

22. Kroos MA, Van der Kraan M, Van Diggelen OP, Kleijer WJ, Reuser AJ, Van den Boogaard, et al. Glycogen storage disease type II: frequency of three common mutant alleles and their associated clinical phenotypes studied in 121 patients. J Med Genet. 1995;32:836-7.

23. Montalvo AL, Bembi B, Donnarumma M, Filocamo M, Parenti G, Rossi M, et al. Mutation profile of the GAA gene in 40 Italian patients with late onset glycogen storage disease type II. Hum Mutat. 2006;27:999-1006.

24. Gort L, Coll MJ, Chabás A. Glycogen storage disease type II in Spanish patients: high frequency of c.1076-1GC mutation. Mol Genet Metab. 2007;92:183-7.

25. Joshi PR, Gläser D, Schmidt S, Vorgerd M, Winterholler M, Eger $\mathrm{K}$, et al. Molecular diagnosis of German patients with late-onset glycogen storage disease type II. J Inherit Metab Dis. 2008;31 Suppl. 2:261-5.

26. Huie ML, Chen AS, Tsujino S, Shanske S, DiMauro S, Engel AG, et al. Aberrant splicing in adult onset glycogen storage disease type II (GSDII): molecular identification of an IVS1 $(-13 \mathrm{~T} \rightarrow \mathrm{G})$ mutation in a majority of patients and a novel IVS10 $(+1 \mathrm{GT} \rightarrow \mathrm{CT})$ mutation. Hum Mol Genet. 1994;3:2231-6.

27. Yang CC, Chien YH, Lee NC, Chiang SC, Lin SP, Kuo YT, et al. Rapid progressive course of later-onset Pompe disease in Chinese patients. Mol Genet Metab. 2011;104:284-8.

28. Park HD, Lee DH, Choi TY, Lee YK, Lee SY, Kim JW, et al. Three patients with glycogen storage disease type II and the mutational spectrum of GAA in Korean patients. Ann Clin Lab Sci. 2013;43:311-6.

29. Loureiro Neves F, Garcia PC, Madureira N, Araújo H, Rodrigues $F$, Estêvão $M H$, et al. Juvenile pompe disease: retrospective clinical study. Acta Med Port. 2013;26:361-70.

30. Oda E, Tanaka T, Migita O, Kosuga M, Fukushi M, Okumiya T, et al. Newborn screening for Pompe disease in Japan. Mol Genet Metab. 2011;104:560-5.

31. Becker JA, Vlach J, Raben N, Nagaraju K, Adams EM, Hermans $M M$, et al. The African origin of the common mutation in African American patients with glycogen-storage disease type II. Am J Hum Genet. 1998;62:991-4.

32. Liu X, Wang Z, Jin W, Lv H, Zhang W, Que C, et al. Clinical and GAA gene mutation analysis in mainland Chinese patients with late-onset Pompe disease: identifying C.2238G > C as the most common mutation. BMC Med Genet. 2014;15:141.

33. Angelini C, Semplicini C, Ravaglia S, Bembi B, Servidei S, Pegoraro EA, et al. Observational clinical study in juvenile-adult glycogenosis type 2 patients undergoing enzyme replacement therapy for up to 4 years. J Neurol. 2012;259:952-8.

34. Regnery C, Kornblum C, Hanisch F, Vielhaber S, Strigl-Pill N, Grunert B, et al. 36 Months observational clinical study of 38 adult Pompe disease patients under alglucosidase alfa enzyme replacement therapy. J Inherit Metab Dis. 2012;35:837-45.

35. van der Ploeg AT, Clemens PR, Corzo D, Escolar DM, Florence J, Groeneveld GJ, et al. A randomized study of alglucosidase alfa in late-onset Pompe's disease. $\mathrm{N}$ Engl J Med. 2010;362:1396-406, http://dx.doi.org/10.1056/ NEJMoa0909859.

36. Ravaglia S, Pichiecchio A, Ponzio M, Danesino C, Saeidi Garaghani K, Poloni GU, et al. Changes in skeletal muscle qualities during enzyme replacement therapy in late-onset type II glycogenosis: temporal and spatial pattern of mass vs. strength response. J Inherit Metab Dis. 2010;33:737-45.

37. Wokke JH, Escolar DM, Pestronk A, Jaffe KM, Carter GT, van den Berg LH, et al. Clinical features of late-onset Pompe disease: a prospective cohort study. Muscle Nerve. 2008;38:1236-45.

38. Heresi GA, Dweik RA. Strengths and limitations of the six-minute-walk test: a model biomarker study in idiopathic pulmonary fibrosis. Am J Respir Crit Care Med. 2011;183:1122-4.

39. ATS Committee on Proficiency Standards for Clinical Pulmonary Function Laboratories. ATS statement: guidelines for the sixminute walk test. Am J Respir Crit Care Med. 2002;166: $111-7$.

40. Manganelli F, Ruggiero L. Clinical features of Pompe disease. Acta Myol. 2013;32:82-4.

41. van der Beek NA, van Capelle $\mathrm{Cl}$, van der Velden-van Etten $\mathrm{KI}$, Hop WC, van den Berg B, Reuser AJ, et al. Rate of progression and predictive factors for pulmonary outcome in children and adults with Pompe disease. Mol Genet Metab. 2011;104:129-36, http://dx.doi.org/10.1016/j.ymgme.2011.06.012.

42. Hobson-Webb LD, Jones HN, Kishnani PS. Oropharyngeal dysphagia may occur in late-onset Pompe disease, implicating bulbar muscle involvement. Neuromuscul Disord. 2013;23:319-23.

43. Kishnani PS, Steiner RD, Bali D, Berger K, Byrne BJ, Case LE, et al. Pompe disease diagnosis and management guideline. Genet Med. 2006;8:267-88.

44. Barba-Romero MA, Barrot E, Bautista-Lorite J, Gutierrez-Rivas E, Illa I, Jimenez LM, et al. Clinical guidelines for late-onset Pompe disease. Rev Neurol. 2012;54:497-507.

45. Toscano A, Montagnese F, Musumeci O. Early is better? A new algorithm for early diagnosis in late onset Pompe disease (LOPD). Acta Myol. 2013;32:78-81.

46. Quanjer PH, Stanojevic S, Cole TJ, Baur X, Hall GL, Culver BH, et al. Multi-ethnic reference values for spirometry for the 3 95-yr age range: the global lung function 2012 equations. Eur Respir J. 2012;40:1324-43. 